\title{
The Rvi15 (Vr2) Apple Scab Resistance Locus Contains Three TIR-NBS-LRR Genes
}

\author{
Paolo Galli, ${ }^{1}$ Andrea Patocchi, ${ }^{2}$ Giovanni Antonio Lodovico Broggini, ${ }^{1}$ and Cesare Gessler ${ }^{1}$ \\ ${ }^{1}$ Plant Pathology, Institute of Integrative Biology, ETH-Z, Universitaetstrasse 2, CH 8092 Zurich; ${ }^{2}$ Agroscope Changins- \\ Wädenswil Research Station (ACW), Schloss, $\mathrm{CH}-8820$ Wädenswil, Switzerland
}

Submitted 29 July 2009. Accepted 23 December 2009.

Scab caused by the pathogen Venturia inaequalis is considered the most important fungal disease of cultivated apple (Malus $\times$ domestica Borkh.). In all, 16 monogenic resistances against scab have been found in different Malus spp. and some of them are currently used in apple breeding for scab-resistant cultivars. However, the self incompatibility and the long generation time of Malus spp. together with the high standards of fruit quality demanded from the fresh market render the breeding of high-quality cultivars in apple a long and expensive task. Therefore, the cloning of disease resistance genes and the use of the cloned genes for the transformation of high-quality apple cultivars could be an approach to solve these drawbacks. We report the construction of a bacterial artificial chromosome (BAC) contig spanning the $R v i 15$ ( $V r 2)$ apple scab resistance locus using two GMAL 2473 BAC libraries. A single BAC clone of the contig was sufficient to span the resistance locus. The BAC clone was completely sequenced, allowing identification of a sequence of $48.6 \mathrm{~kb}$ going from the two closest markers (ARGH17 and 77G20RP) bracketing Rvi15 (Vr2). Analysis of the 48.6-kb sequence revealed the presence of three putative genes characterized by a Toll and mammalian interleukin-1 receptor protein nucleotide-binding site leucine-rich repeat structure. All three genes were found to be transcribed.

Apple (Malus $\times$ domestica Borkh.) is one of the economically most important perennial fruit crops of the temperate zone (MacHardy 1996). The long generation time and the selfincompatibility of apple make breeding programs difficult and time consuming. Relevant efforts have been invested in the last century to generate apple cultivars resistant to apple scab, the most important fungal disease in apple orchards, which is caused by the ascomycete Venturia inaequalis (MacHardy 1996). The most successful breeding program involved the apple scab resistance gene Rvi6 ( $V f$ ) found in the small-fruited "wild" Malus selection Malus floribunda 821 (Crandall 1926). (Please note that, throughout this article, we will indicate both names of the apple scab resistances: the new name following the nomenclature system proposed by Bus and associates [2009] and the historical name in parentheses). Crandall started a resistance breeding program by crossing $M$. floribunda 821 with 'Rome Beauty' in 1914 (Crandall 1926). Almost all the scab-resistant cultivars grown today derived from this breeding program (MacHardy 1996). However, after almost a century of breeding efforts, none of the produced cultivars had a consid-

Corresponding author: Andrea Patocchi;

E-mail: andrea.patocchi@acw.admin.ch erable impact on production by replacing major susceptible cultivars (Gardiner et al. 2007). In addition, races of $V$. inaequalis able to overcome the Rvi6 ( $V f$ ) resistance have been identified (Parisi et al. 1993; Roberts and Crute 1994; Bénaouf and Parisi 2000), indicating that new resistance breeding strategies have to be set up carefully. A promising way to reach durable resistance is the incorporation of two or more resistance $(R)$ genes (pyramiding) in the same cultivar (MacHardy et al. 2001). This strategy should delay or even prevent the breakdown of the $R$ genes and create cultivars carrying a durable resistance to apple scab. However, breeding such cultivars containing pyramided $R$ genes with a good impact on the market will require many years and complex crosses.

Recently, researchers have developed in vitro strategies, such as the cisgenesis, to insert $R$ genes in cultivars, avoiding the difficulties of classical breeding (Jacobsen and Schouten 2007). In this genetic modifying approach, $R$ genes, which are found in crossable species, are inserted in cultivars with their native promoters and terminators. During the transformation process, foreign genes are used but they will be removed from the final product. Therefore, it has been argued that this technology would produce plants that, if released in the environment, are as safe as plants obtained by traditional breeding (Jacobsen and Schouten 2007). Safety and ethical concerns generating from traditional transgenesis would then mostly be solved with this type of genetic modification (Jacobsen and Schouten 2007). Recently, Gessler and associates (2009) reported the development of the first apple-scab-resistant cisgenic apple ('Gala') transformed with the HcrVf2 (conferring Rvi6 ( $V f$ ) resistance), demonstrating the feasibility of the cisgenic approach in apple. However, cisgenesis has a disadvantage compared with traditional breeding because it requires the cloning of the $R$ genes.

A successful strategy for the isolation of $R$ genes is the mapbased cloning procedure. This methodology relies on the availability of markers closely linked to the $R$ gene, from which chromosome walking is undertaken to isolate genomic clones from a library with large inserts to span the region of the gene of interest. After that, sequencing the clones and bioinformatics analysis of the sequences will provide the sequences of candidate $R$ genes. Finally, silencing or complementation experiments are used to identify which of the candidate genes is conferring the resistance. This strategy has been adopted to clone many $R$ genes in different species, among others Pto in tomato (Martin et al. 1993), RPS2 in Arabidopsis thaliana (Bent at al. 1994), Xa21 in rice (Song et al. 1995), and Lrlo from hexaploid wheat (Feuillet et al. 2003).

Until now, only one $R$ gene has been cloned in apple, the Rvi6 $(V f)$ apple scab resistance gene located on linkage group (LG) 1. Upon inoculation with scab and depending on the background, 
plants carrying Rvi6 ( Vf) display phenotypes going from no symptoms to chlorosis to necrosis and chlorosis with limited sporulation. Two independent series of works arrived at similar results by using different bacterial artificial chromosome (BAC) libraries for chromosome walking. The construction of a 550-kb BAC contig spanning the Rvi6 ( $V f$ ) resistance locus (Patocchi et al. 1999) using a BAC library generated from 'Florina' genomic DNA (Vinatzer et al. 1998) started the first series of works. After that, Vinatzer and associates (2001), using the BAC inserts of the contig as a probe to screen a large cDNA library, could isolate three putative genes (HcrVf1, HcrVf2, and HcrVf3) that showed similarity to the cloned Cladosporium fulvum $(C f) R$ gene from tomato. The expression of one of the candidate resistance genes (HcrVf2) under the Cauliflower mosaic virus 35S promoter in a susceptible apple (Gala) demonstrated that HcrVf2 is sufficient to confer Rvi6 ( $V f$ ) scab resistance (Belfanti et al. 2004). Furthermore, Szankowski and associates (2009) tested the ability of three $H v r V f 2$ promoter constructs $(115,288$, and $779 \mathrm{bp}$ of the $5^{\prime}$ untranslated region of $\mathrm{HcrVf2}$ ) associated with the HcrVf2 coding region to confer apple scab resistance to the susceptible cvs. Gala and Elstar. Highly scab-resistant cultivars were obtained with promoter sequences of 288 and $779 \mathrm{bp}$. In a similar study, Malnoy and associates (2008) declared that both HcrVfl and HcrVf2 controlled by $2 \mathrm{~kb}$ of their native promoter are able to confer apple scab resistance once introduced in 'Galaxy' and 'McIntosh'. The second series of work started with the construction of a smaller BAC contig of $290 \mathrm{~kb}$ spanning the resistance locus (Xu and Korban 2002). The sequencing of the BAC subclones positive to a screening with total labeled cDNA allowed the isolation of three genes expressed in this region (Vfal, Vfa2, and Vfa4). Vfal and Vfa2 are identical to HcrVfl and HcrVf2 identified previously by Vinatzer and associates (2001).

To develop cisgenic apple cultivars with pyramided resistance genes against apple scab, the cloning of other functionally different resistance genes is required. The Rvil5 ( Vr2) apple scab resistance locus, which elicits a slow hypersensitive response (HR) (Galli et al. in press, b), has been mapped on the top of the LG 2 in the GMAL 2473 accession (Patocchi et al. 2004). The gene has been found to segregate for a single dominant locus (Galli et al. in press, a). Further, a high-resolution genetic map based on 989 progeny of a cross 'Golden Delicious' $\times$ GMAL 2473 has been developed for this resistance locus using 4 published markers and 10 markers derived from the sequence of a Florina BAC clone (36I17, $100 \mathrm{~kb}$ ), which was found sufficient to span completely the homolog Rvi15 ( $V r 2)$ region (Galli et al. in press, a). The two closest markers to Rvi15 ( $V r 2)$, ARGH17 and GmTNL1, were derived from resistance gene homolog $(\mathrm{RGH})$ sequences and have been mapped on both site of the resistance locus at 0.3 centimorgans (cM) (three recombinants) and $0.2 \mathrm{cM}$ (two recombinants), respectively.

In this article, we report the construction of two GMAL 2473 BAC libraries, which we screened with the two Rvil5 (Vr2) flanking markers (ARGH17 and GmTNL1) to develop a BAC contig spanning the resistance region. The BAC clone (32A4) found to span the Rvil5 (Vr2) locus was then sequenced and the open reading frames (ORF) found in the region of the Rvi15 ( Vr2) resistance were characterized.

\section{RESULTS}

\section{Construction and characterization of the BAC libraries.}

The first BAC library was constructed from HMW DNA partially digested with 15 units of EcoRI enzyme per reaction. This amount of enzyme was judged to be the best condition to recover the highest amount of partially digested DNA with a size of between 200 and $500 \mathrm{~kb}$. After DNA size selection, the ligations of the partially digested DNA produced, on average, 140 white colonies per microliter of ligation. Testing 84 random clones, the insert size ranged between 40 and $140 \mathrm{~kb}$, resulting in an average of $78 \mathrm{~kb}$. Then, 32,256 clones were produced and picked, providing 3.3 apple haploid genome equivalents $(769 \mathrm{Mbp} / 1 \mathrm{C}$ Malus $\times$ domestica) (Arumuganathan and Earle 1991) (Table 1).

The second HindIII BAC library constructed at Amplicon Express Inc. consists of 36,864 clones. Testing 28 random clones, the insert size ranged between 80 and $210 \mathrm{~kb}$, resulting in an average of $135 \mathrm{~kb}$ and, thus, providing 6.5 apple haploid genome equivalents (Table 1).

\section{Construction of the BAC contig spanning the Rvi15 ( $\mathrm{Vr} 2)$ resistance locus.}

The two high-density filters containing all 32,256 clones of the first BAC library were first screened with the GmTNL1 marker mapping at $0.2 \mathrm{cM}$ from the Rvil5 ( Vr2) resistance gene. In all, $39 \mathrm{BAC}$ clones hybridized to the probe; however, no BAC could be confirmed to carry the GmTNL1 marker. Therefore, the BAC library was hybridized with ARGH17. Seven positive clones were found; however, only one BAC clone, 48K16 (70kb), was found to carry the ARGH17 marker. AluI digestion of the ARGH17 amplicon of 48K16 indicated that this BAC clone derives from the chromosome in repulsion with the resistance. The primer pair designed on the T7 extremity of the $48 \mathrm{~K} 16$ BAC was found to amplify a specific 700-bp band linked with the Rvil5 ( $V r 2)$ resistance (Table 2). This was the only polymorphic marker (48K16T7) that could be developed on the BAC clone insert ends. Mapping of the marker revealed that it co-segregates with the marker ARGH17; thus, not allowing the orientation of the BAC on the genetic map. Attempts to continue the chromosome walking from the extremities of this BAC were unsuccessful because all the developed probes were too unspecific and hybridized to dozens of BAC. Because the chromosome walk could not be continued from the ARGH17 side and no BAC was found carrying the GmTNL1 marker, the library was judged unsuitable to clone Rvil5 ( $V r 2)$ and the construction of a second GMAL 2473 library was outsourced.

The second BAC library was also hybridized with the ARGH17 and the GmTNL1 markers. In all, 10 BAC clones out of 35, hybridizing to either ARGH17 (17 BAC) or GmTNL1 (28 BAC), could be confirmed by colony polymerase chain reaction (PCR) carrying the two markers (ARGH17: seven BAC and GmTNL1: three BAC). BAC 32A4, 41A24, 43M10, and $77 \mathrm{G} 18$ were found to contain the resistant allele of ARGH17, while three (7A2, 33C17, and 35O8) contained the susceptible one. $45 \mathrm{I} 17$ was the only BAC found to carry the GmTNL1 resistant allele while 64N4 and 57F14 contained the susceptible one. Insert extremities of the positive BAC clones were sequenced and markers were developed. Markers were used to test the presence of the insert end in the other BAC by PCR. Markers designed on the T7 insert ends of the "resistant" BAC $43 \mathrm{M} 10$ and $45 \mathrm{I} 17$ were found to amplify only the BAC on which they were developed and, therefore, were considered to be external to the contig. All the other BAC insert-end markers

Table 1. Properties of the two GMAL 2473 bacterial artificial chromosome (BAC) libraries

\begin{tabular}{lcccc}
\hline BAC library (rest. & $\begin{array}{c}\text { No. of } \\
\text { Enzyme) }\end{array}$ & $\begin{array}{c}\text { No. of BAC } \\
\text { clones } \\
\text { tested }\end{array}$ & $\begin{array}{c}\text { Average } \\
\text { BAC insert } \\
\text { size (kb) }\end{array}$ & $\begin{array}{c}\text { Haploid } \\
\text { genome } \\
\text { equivalents }\end{array}$ \\
\hline First (EcoRI) & 32,256 & 84 & $78 \pm 34$ & 3.3 \\
Second (HindIII) & 36,864 & 28 & $135 \pm 27$ & 6.5 \\
\hline
\end{tabular}


amplified from other BAC, allowing the construction of the BAC contig represented in Figure 1 . To check the quality of the constructed contig, EcoRI and HindIII fingerprint analysis were performed. The analysis confirmed that: $41 \mathrm{~A} 24$ is a subclone of 32A4; 32A 4 overlaps with $45 \mathrm{I} 17$ as well as $43 \mathrm{M} 10$ and 77G18. Finally, EcoRI and HindIII fingerprints were hybrid- ized with probes obtained from ARGH17, 32A4 RP, and 41A24 T7. All these controls indicated that the Rvil5 ( $V r 2)$ resistance locus was spanned with overlapping BAC clones, the minimal BAC required being $32 \mathrm{~A} 4$ and $45 \mathrm{I} 17$. The same analysis performed with the BAC clones derived from the "susceptible" chromosome indicated that the BAC contig constructed from

Table 2. Polymorphic markers developed on bacterial artificial chromosome (BAC) extremities

\begin{tabular}{|c|c|c|c|c|c|c|}
\hline \multicolumn{2}{|l|}{ Marker } & \multirow[b]{2}{*}{ Primers $^{b}$} & \multirow[b]{2}{*}{ Annealing } & \multicolumn{2}{|c|}{ GMAL 2473} & \multirow{2}{*}{$\begin{array}{c}\text { 'Golden Delicious' } \\
\text { Alleles }^{\mathrm{c}}\end{array}$} \\
\hline Name & Type $^{\mathbf{a}}$ & & & $\operatorname{Res}^{\mathrm{c}}$ & Susc $^{c}$ & \\
\hline 48K16T7 & $\begin{array}{l}\text { SCAR } \\
\ldots\end{array}$ & $\begin{array}{l}\text { F: } 5^{\prime} \text {-cactaaggttccaggcttgg-3' } \\
\text { R: } 5^{\prime} \text {-tgcaaggatgatctatgaatcg-3' }\end{array}$ & $55^{\circ} \mathrm{C}$ & 608 & 535 & $\approx 550$ and 0 \\
\hline 41A24T7 & SCAR & $\begin{array}{l}\text { F: } 5^{\prime} \text {-catcattccaccaagatcc- } 3^{\prime} \\
\text { R: } 5^{\prime} \text {-ttgaagcagagcgtacatcc- } 3^{\prime}\end{array}$ & $60^{\circ} \mathrm{C}$ & 580 & 0 & $\approx 650$ and 0 \\
\hline 41A24RP & $\begin{array}{l}\text { SCAR } \\
\ldots\end{array}$ & $\begin{array}{l}\text { F: } 5^{\prime} \text {-ctgacatggcagtacgtg- } 3^{\prime} \\
\text { R: } 5^{\prime} \text {-ttcgtgctaattgttgtgctac- } 3^{\prime}\end{array}$ & $60^{\circ} \mathrm{C}$ & 584 & 0 & $\approx 450$ and 0 \\
\hline 43M10RP & $\begin{array}{l}\text { SCAR } \\
\ldots\end{array}$ & $\begin{array}{l}\text { F: } 5^{\prime} \text {-tcagaaattgaggagggagag- } 3^{\prime} \\
\text { R: } 5^{\prime} \text {-caattagccgcaatgtgaag- } 3^{\prime}\end{array}$ & $60^{\circ} \mathrm{C}$ & $\begin{array}{l}537 \\
318\end{array}$ & $\begin{array}{r}0 \\
320\end{array}$ & $\begin{array}{c}\text { None } \\
320 \text { and } 0\end{array}$ \\
\hline 77G20RP & $\begin{array}{l}\text { SSR } \\
\text { Multilocus }\end{array}$ & $\begin{array}{l}\text { F: } 5^{\prime} \text {-gaacatgaatcagggaagc--3' } \\
\text { R: } 5^{\prime} \text {-aggtagcccaactctttatgagg- } 3^{\prime}\end{array}$ & $55^{\circ} \mathrm{C}$ & $276^{\mathrm{d}}$ & $280^{\mathrm{d}}$ & 282 and 270 \\
\hline 21K14T7 & $\begin{array}{l}\text { SNP } \\
\ldots\end{array}$ & $\begin{array}{l}\text { F: } 5^{\prime} \text {-cccaaaggaagtgcaaagag- } 3^{\prime} \\
\text { R: } 5^{\prime} \text {-cggaatgactaaattgatgtgg- } 3^{\prime}\end{array}$ & $60^{\circ} \mathrm{C}$ & G (223) & A (223) & $\mathrm{A}$ and 0 \\
\hline $8 \mathrm{~K} 11 \mathrm{RP}$ & $\begin{array}{l}\text { SCAR } \\
\ldots\end{array}$ & $\begin{array}{l}\text { F: } 5^{\prime} \text {-ttgacccataaaggctttcc- } 3^{\prime} \\
\text { R: } 5^{\prime} \text {-gccaagagctccaggacac- } 3^{\prime}\end{array}$ & $60^{\circ} \mathrm{C}$ & 562 & 564 & 564 and 0 \\
\hline
\end{tabular}

${ }^{\text {a }}$ SCAR = sequence characterised amplified region; SSR = simple-sequence repeat; SNP = single nucleotide polymorphism.

${ }^{\mathrm{b}}$ Underlined primer was used to detect the SNP ( $\mathrm{F}=$ Forward and $\mathrm{R}=$ Reverse).

${ }^{\mathrm{c}}$ Size or position of the nucleotide difference followed for mapping (Res = allele linked with the resistance, Susc= allele in repulsion with the resistance).

${ }^{d}$ Alleles of the 77G20RPbis marker co-segregating with the ARGH17 marker.

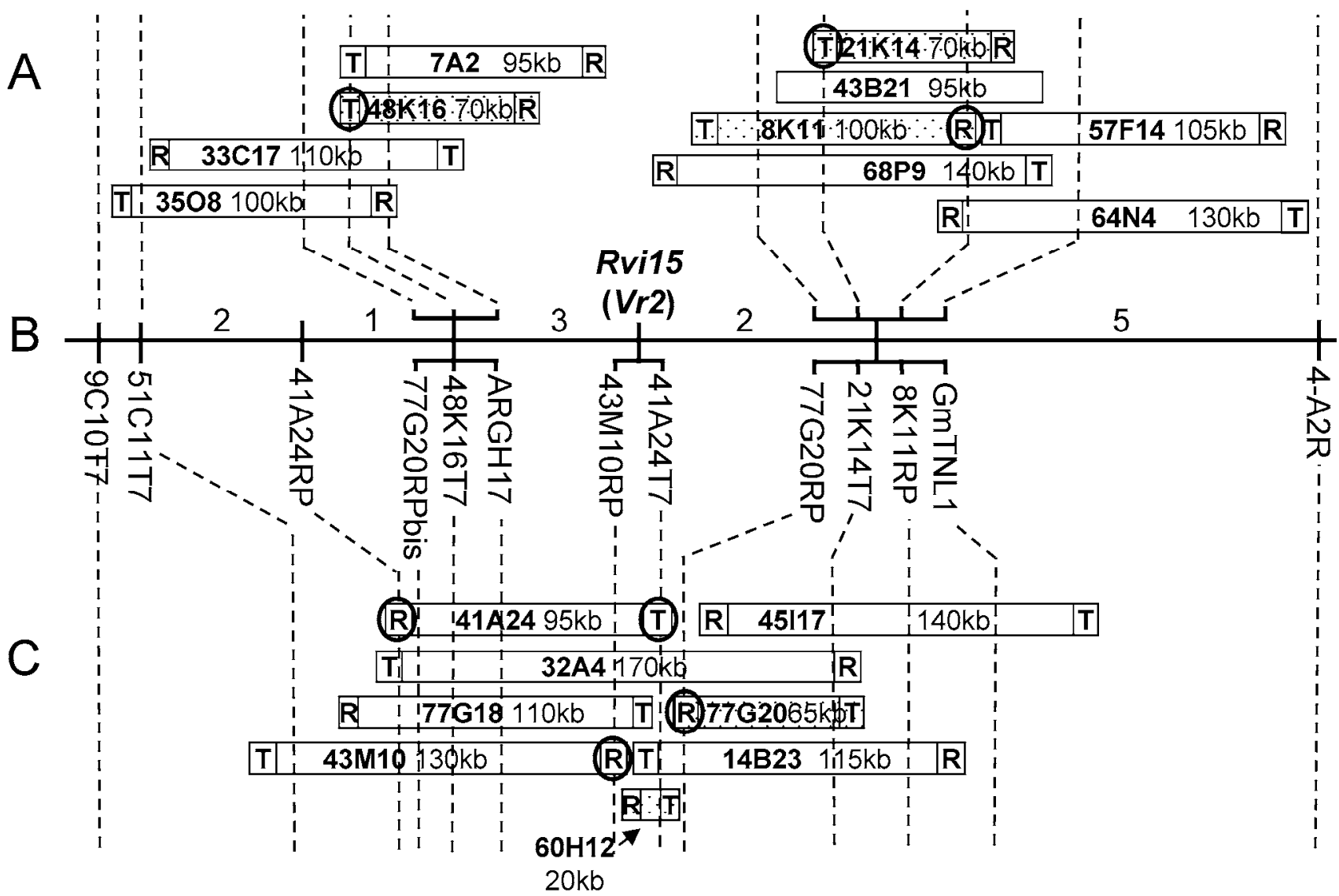

Fig. 1. Bacterial artificial chromosome (BAC) contigs spanning the Rvil5 ( $V r 2)$ region and genetic map of the resistance gene. A, Contig constructed with BAC clones carrying inserts derived from the chromosome not carrying the resistance. B, Genetic map of Rvil5 ( $V r 2)$. Numbers indicate the number of recombinants detected in 989 progenies of the cross 'Golden Delicious' $\times$ GMAL 2473 (Galli et al. in press, a). C, Contig constructed with BAC clones carrying inserts derived from the chromosome carrying the resistance. BAC extremities, on which a polymorphic marker was developed, are circled and reported with a dashed line on the genetic map. Stippled BAC were found by screening of the first BAC library whereas white BAC were isolated from the second BAC library. T: T7 BAC insert-end; R: RP BAC insert-end. 
ARGH17 does not overlap with the one constructed from GmTNL1 (Fig. 1).

In an attempt to reduce the Rvil5 ( $\mathrm{Vr} 2)$ region, the markers found to be polymorphic (41A24 T7, 41A24 RP, and 43M10 RP) were mapped (Table 2). The 41A24 RP end mapped between the 51C11 T7 and the ARGH17 markers at one recombinant from ARGH17. The other two markers co-segregated with the Rvil5 ( $V r 2)$ resistance.

Two additional hybridizations of the two BAC libraries were carried out using 41A24 T7 and 32A4 RP as a probe in the attempt to identify additional BAC and to develop on their insert ends additional polymorphic markers to reduce the Rvi15 ( Vr2) region. Two BAC clones $(60 \mathrm{H} 12$ originating from the first library and 14B23 originating from the second library) were found carrying the 41A24 T7 marker and were then integrated into the resistant BAC contig. Five new BAC (8K11, $21 \mathrm{~K} 14$, and $77 \mathrm{G} 20$ originating from the first library and $43 \mathrm{~B} 21$ and $68 \mathrm{P} 9$ originating from the second library) were found by screening the BAC libraries using 32A4 RP as probe. Because the 32A4 RP is not a polymorphic marker, three new polymorphic markers were developed on the $21 \mathrm{~K} 14 \mathrm{~T} 7,8 \mathrm{~K} 11$ RP, and 77G20 RP BAC extremities (Table 2), allowing us to distinguish the "resistant" and the "susceptible" BAC: 77G20 is derived from the resistant chromosome, while the others are derived from the susceptible one $(8 \mathrm{~K} 11,21 \mathrm{~K} 14,43 \mathrm{~B} 21$, and 68P9). All three markers were mapped at two recombinants from the Rvil5 ( $V r 2)$ co-segregating with GmTNL1. However, the 77G20 RP marker was found to be closer (physically; see orientation of the BAC in Figure 1) to Rvil5 ( $V r 2)$ than the other co-segregating markers, allowing restriction of the Rvil5 ( $V r 2$ ) region from ARGH17 to 77G20 RP. Therefore, the BAC $32 \mathrm{~A} 4$ is sufficient to span the whole Rvil5 ( $V r 2)$ apple scab resistance locus.

\section{BAC clone sequencing and characterization of the Rvi15 ( Vr2) candidate genes.}

The BAC clone $32 \mathrm{~A} 4$ was shotgun sequenced with a $10 \mathrm{x}$ coverage and first assembled in nine contigs. After sequence quality control and alignment of the markers linked with the Rvil5 ( $V r 2)$ resistance, gaps between the sequences in the region delimited by ARGH17 and 77G20 RP were filled by primer walking on 32A4. This allowed the reduction of the number of contig to four of 2,061, 136,255, 7,746, and 22,376 bp (in order starting from the T7 BAC extremity). ARGH17 and 77G20 RP markers were both found on the largest contig, delimiting the Rvil5 ( $V r 2)$ resistance region within a 48.6-kb gap-free sequence (Fig. 2A and B). In all, 17 ORF were predicted in this sequence; however, only 3 of them showed similarities to nucleotide and amino acid sequences deposited at the National Center for Biotechnology Information (NCBI) database and presented structures already found in cloned resistance genes. The three putative genes, called $V r 2-A, V r 2-B$, and $V r 2-C$, were all found to share high similarity to the $M$. baccata MbR7 gene (AY363617). They also showed the same

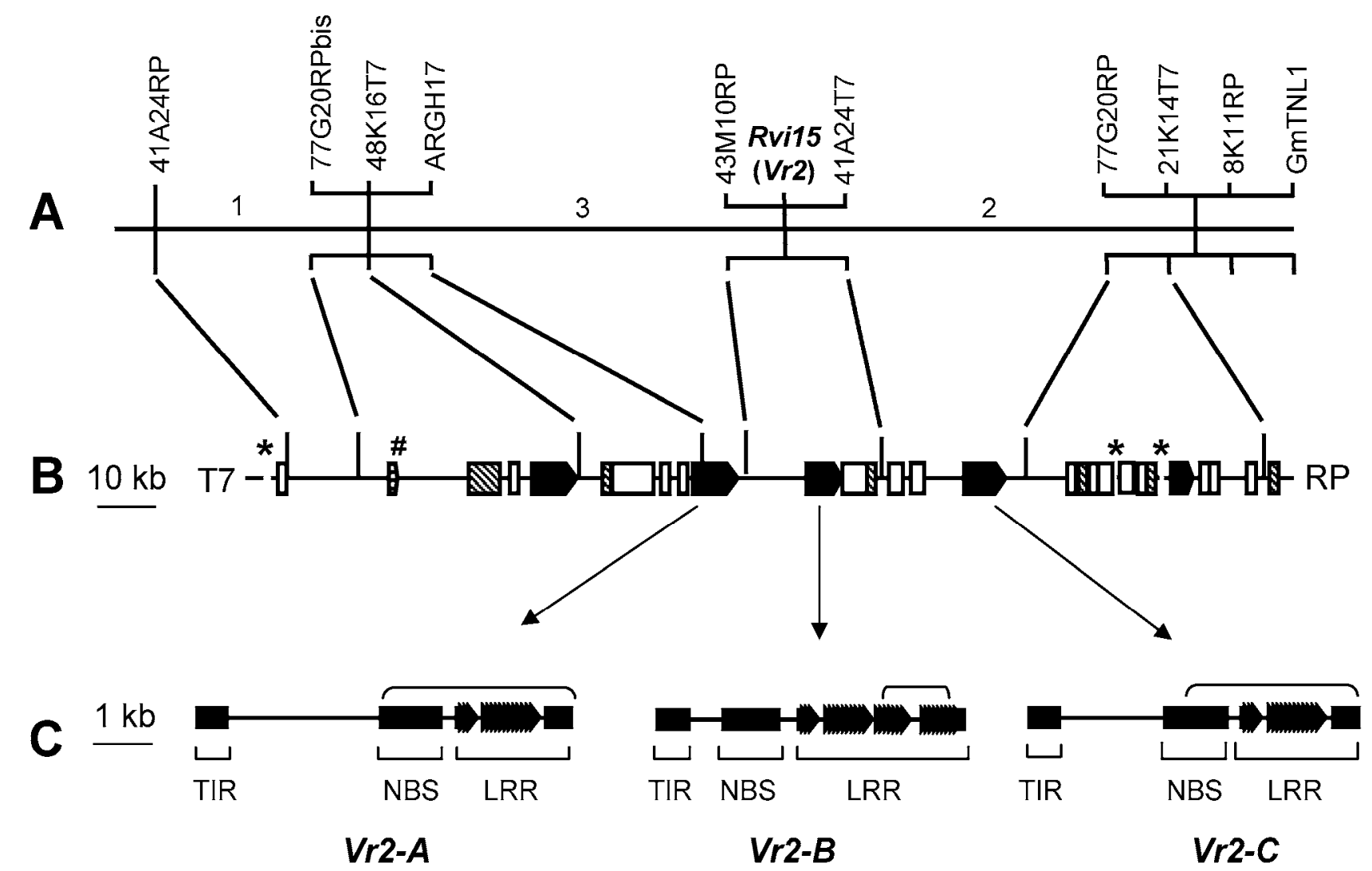

Fig. 2. Integrated scheme of the Rvil5 ( Vr2) genetic map, physical position of the three resistance gene homologs (RGHs) identified in the $R v i 15$ ( $V r 2$ ) region and structure of the RGHs. A, Genetic map of Rvi15 ( $V r 2)$. Numbers indicate the numbers of recombinants detected in 989 progenies of the cross 'Golden Delicious' $\times$ GMAL 2473 (Galli et al. in press, a). B, Schematic representation of markers position and position of the protein predicted on the 32A4 bacterial artificial chromosome (BAC) sequence. ARGH17 and 77G20RP, which are the markers mapping closer (physically) to the resistance, delimit the Rvi15 (Vr2) region to $48.6 \mathrm{~kb}$. Black boxes indicate Drosophila Toll and mammalian interleukin-1 receptor (TIR) nucleotide-binding site (NBS) leucine-rich repeat (LRR) putative genes while white boxes represent putative transposable elements. Dashed boxes indicate truncated TIR-NBS-LRR genes whereas prediction of a putative protein phosphatase is indicated with a hash. The asterisk indicates the position of the gap present in the $32 \mathrm{~A} 4 \mathrm{BAC}$ sequence. C, Exon-intron structure of the three Rvil5 ( $V r 2)$ candidate genes called $V r 2-A, V r 2-B$, and $V r 2-C$. TIR-NBS-LRR domains and the parts of the predicted open reading frames (ORF) confirmed by reverse-transcription polymerase chain reaction (upper parenthesis) are indicated. The position of the LRR motifs are reported as triangles in the three predicted ORF. 
orientation on the contig and the same structure: an $\mathrm{N}$ terminus with homology to the intracellular domain of the Drosophila Toll and mammalian interleukin-1 receptor proteins (TIR) (Whitham et al. 1994), a central nucleotide-binding site (NBS), and a C-terminal leucine-rich repeat (LRR) domain (Fig. 2C).

Vr2-A, which contains the ARGH17 marker in its NBS domain, was predicted with a coding sequence of 3,273 nucleotides (1,091 amino acids) composed of five exons and covering 6,228 nucleotides of genomic DNA. $V r 2-B$ was predicted with a coding sequence of 4,032 nucleotides (1,344 amino acids) composed of six exons and covering 5,143 nucleotides of genomic DNA. Finally, $V r 2-C$ was predicted with a coding sequence of 3,297 nucleotides (1,099 amino acids) composed of five exons and covering 5,445 nucleotides of genomic DNA (Fig. 3). The three candidate genes shared an average identity at nucleotide level of $58 \%$ (62\% at amino acid level) for the predicted ORF.

TIR domains of the three candidate genes were between 229 and 232 amino acids long and shared an average identity of $82 \%$ at the amino acid level, presenting all four typical conserved functional motifs (Fig. 3). The size of the NBS domain of $V r 2-B$ and $V r 2-C$ is 312 amino acids while that of $V r 2-A$ is 3 amino acids longer (315 amino acids). The NBS domains share an average identity of $76 \%$ and contain all eight conserved func- tional motifs (Fig. 3). The highest variability was found in the LRR domains, sharing an average amino acid identity of $47 \%$. Large differences in length of the LRR domain were observed: 547 amino acids for $V r 2-A, 801$ amino acids for $V r 2-B$, and 555 amino acids for $V r 2-C$. The LRR domain of the $V r 2-A$ and $V r 2-$ $C$ genes is characterized by 15 imperfect LRR motifs sharing, on average, an amino acid identity of $72,4 \%$. The $V r 2-B$ has a longer LRR domain, consisting of 29 imperfect LRR motifs. This domain of $\operatorname{Vr} 2-B$ is characterized by three distinct blocks containing 12,7 , and 10 repeated motifs, respectively. Labeling the similar LRR motifs between the putative genes from $\mathrm{A}$ to $\mathrm{O}$ reveals that the first and the third block of motifs consists of $\mathrm{C}$ to I with repeated $\mathrm{F}$ to $\mathrm{H}$ motifs whereas, in the second block, only $\mathrm{C}$ to I motifs are present and not the repetition of the $\mathrm{F}$ to $\mathrm{H}$. The eight motifs ( $\mathrm{C}$ to $\mathrm{I}$ ) repeated three ( $\mathrm{C}$ to $\mathrm{E}$ and $\mathrm{I}$ ) or five ( $\mathrm{F}$ to $\mathrm{H})$ times shared an average identity at the amino acid level of $78.5 \%$ (Fig. 3).

\section{Transcription analysis of $\mathrm{Rvi15}(\mathrm{Vr} 2)$ candidate genes.}

Transcription of all the three candidate genes could be proved by reverse-transcription (RT)-PCR (Fig. 4). The same experiment allowed the verification of part of the predicted ORF structure of the three candidate genes by comparing the genomic with the RT-PCR sequences (Fig. 2C). The prediction of the
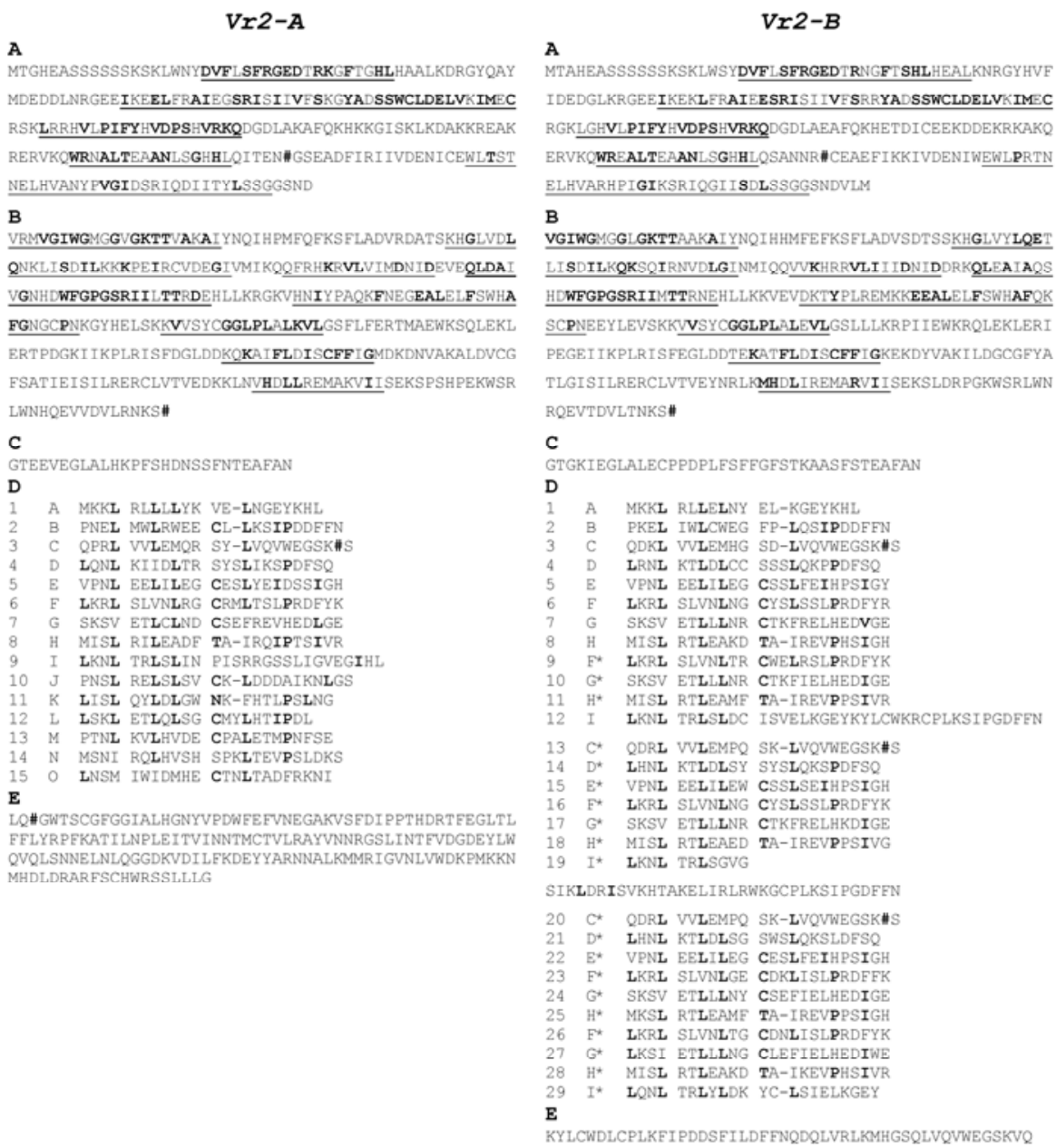

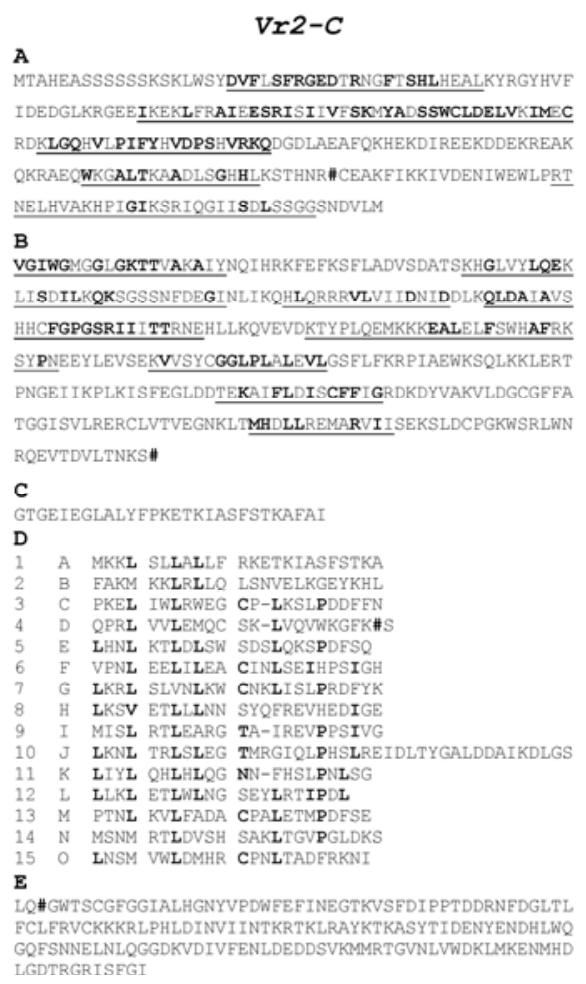

LGDTRGRISFGI

Fig. 3. Amino acid sequence of the predicted full-length transcript of the three Rvi15 ( Vr2) candidates. The amino acid sequence has been divided into five domains: A, N-terminus Drosophila Toll and mammalian interleukin-1 receptor (TIR); B, nucleotide binding site; C, connecting region; D, leucine-rich repeat; and $\mathbf{E}$, the C-terminal region. The conserved motifs of the TIR and NBS domains are underlined in A and B and the amino acid matching the consensus sequence, according to the definitions of Meyers and associates (2003), are indicated in bold. Alignment of the LRR domain has been performed following the cytoplastic LRR consensus LxxL xxLxLxx (N/C/T)x(x)LxxIPxxaxx, indicating the conserved amino acids in bold (Jones and Jones 1997). Similar LRR motifs between the three genes are labeled with letters from A to $\mathrm{O}$; \# and * indicate the intron position and the repeated motifs, respectively, of the $V r 2-B$ LRR domain. 
Vr2-A ORF was confirmed from the NBS domain to the stop codon $(2,511 \mathrm{bp})$. The prediction of $V r 2-B$ was confirmed for the last two exons (829 bp). Finally, the prediction of $V r 2-C$ was confirmed from the NBS domain to the stop codon (2,360 bp).

\section{DISCUSSION}

Construction of the BAC libraries.

Sufficient quantity and quality of HMW DNA of GMAL 2473 to allow the construction of the first BAC library $(32,256$

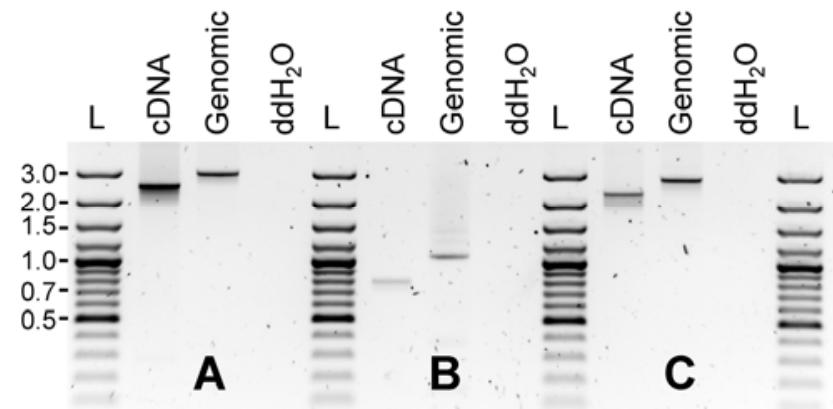

Fig. 4. Reverse-transcription polymerase chain reaction of the three candidate genes for Rvi15 ( $V r 2)$ apple scab resistance. Amplifications were performed from total synthesized cDNA of GMAL 2473, from genomic GMAL 2473 DNA, and using double-distilled $(\mathrm{dd}) \mathrm{H}_{2} \mathrm{O}$ as a negative control. A, Transcription analysis of the $V r 2-A$ candidate gene $(2,511 \mathrm{bp}$ of the cDNA and 2,911 bp of the genomic DNA). B, Transcription analysis of the $\operatorname{Vr2}-B$ candidate gene ( $829 \mathrm{bp}$ of the cDNA and $996 \mathrm{bp}$ of the genomic DNA). C, Transcription analysis of the $V r 2-C$ candidate gene $(2,360 \mathrm{bp}$ of the cDNA and 2,782 bp of the genomic DNA). L = 100-bp ladder (size in base pairs). clones) was obtained by adopting the universal method described by Zhang and associates (1995) with the modifications of Vinatzer and associates (1998) for apple leaves. The average insert size of the BAC clones was estimated to be $78 \mathrm{~kb}$, resulting in a BAC library providing 3.3 apple haploid genome equivalents. However, this BAC library was insufficient to develop a BAC contig spanning the Rvil5 ( Vr2) resistance locus. This is to be ascribed to the small insert size of the BAC clones leading to a relatively small number of apple haploid genome equivalents $(769 \mathrm{Mbp} / 1 \mathrm{C}$ Malus $\times$ domestica $)$ (Arumuganathan and Earle 1991). Frijters and associates (1997) discussed the critical factors of the construction of BAC libraries which can lead to small insert size of BAC clones. We believe that the small size of the first BAC library derived principally from an overloading of the PFGE, which generated an excessive trapping of small DNA fragments. As discussed by Frijters and associates (1997), the presence of small molecules in the selected DNA will transform with much greater efficiency, dropping the average insert size of the BAC clones produced.

\section{Construction of the Rvi15 ( Vr2) contig.}

Both BAC libraries, providing, in total, 9.8 apple haploid genome equivalents, were screened with the two closest markers (ARGH17 and GmTNL1) to the Rvi15 ( $V r 2)$ apple scab resistance locus identified by Galli and associates (in press, a). Two (32A4 and 45I17) of the isolated BAC clones were sufficient to span the whole apple scab resistance locus. Two additional hybridizations were then performed to isolate additional BAC clones of the region. These BAC allowed the development of new markers to further restrict the region where the

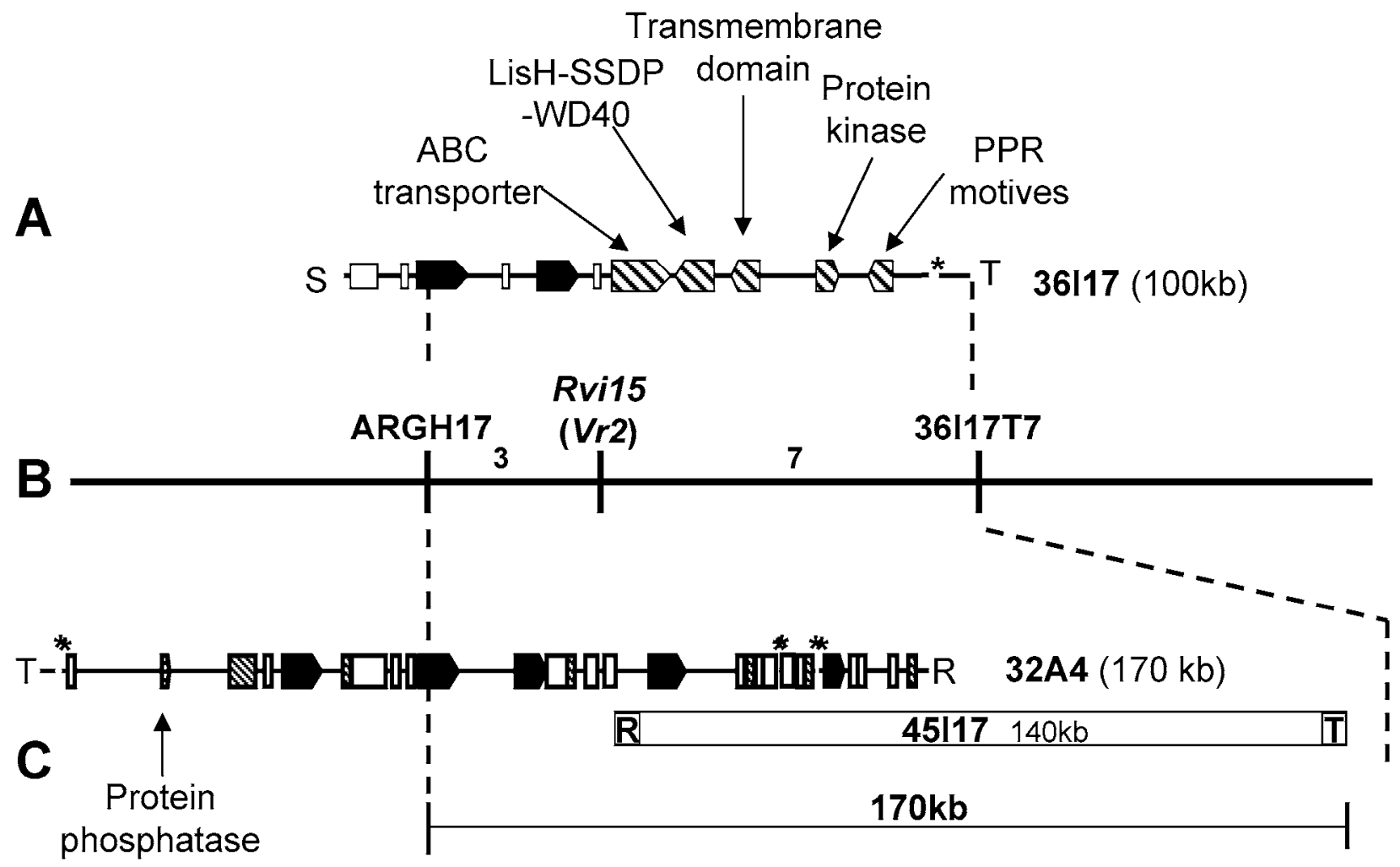

Fig. 5. Comparison between the physical maps of the Rvi15 ( $V r 2)$ homolog regions. A, 36117 bacterial artificial chromosome (BAC) clone spanning the Rvil5 ( $\operatorname{Vr} 2$ ) homolog region of 'Florina' (Galli et al. in press, a). B, Genetic map based on the analysis of 989 progenies of the cross 'Golden Delicious' $\times$ GMAL 2473. Values indicate the number of recombinants detected. C, Physical map spanning the Rvi15 ( $V r 2$ ) resistance locus of GMAL 2473. 'Florina' 36117 and GMAL 2473 32A4 BAC sequences are schematized using black boxes for Drosophila Toll and mammalian interleukin-1 receptor (TIR) nucleotide-binding site (NBS) leucine-rich repeat (LRR) putative genes, white boxes for putative transposable elements, and dashed boxes for truncated TIR-NBSLRR genes or other type of putative protein (described in the figure). The asterisk indicates the position of the gaps present in the BAC sequences. T: T7 BAC insert-end; R: RP BAC insert-end; S: SP BAC insert-end. 
resistance gene lays. BAC clone $45 \mathrm{I} 17$ was found to be from the "hot" region and only 32A4 was further investigated.

However, the screening with the two probes did not allow the completion of the BAC contig with inserts originating from the chromosome in repulsion with the resistance. This suggests that the Rvil5 ( $V r 2)$ homolog region on the susceptible chromosome may be bigger than the corresponding region on the resistant chromosome. Differences in size among Rvil5 (Vr2) homolog regions is also evident when comparing the BAC contig constructed in Florina (Galli et al. in press, a) with the one on the resistant chromosome of GMAL 2473 (Fig. 5). In Florina, $85 \mathrm{~kb}$ are sufficient to span completely the region going from the ARGH17 to the 36I17T7 markers and only two TIR-NBS-LRR (TNL) putative genes were found on the sequenced 36I17 BAC clone (Galli et al. in press, a). In GMAL 2473 , only part of the same region could be spanned with a BAC contig. However, this partial region, with an estimated size of $170 \mathrm{~kb}$, is already twice as big as that of Florina, and four putative TNL genes were identified (Fig. 5). Differences in size and in number of clustered genes between homolog regions in different genotypes are well known. The largest differences have been reported for the maize $R p l$ cluster (1 to 52 homologs per haplotype) (Smith et al. 2004) and the lettuce Dm3 cluster (12 to 32 homologs per haplotype) (Kuang et al. 2004). These differences have been ascribed to the result of tandem duplications between paralog sequences (Michelmore and Meyer 1998). Tandem duplication could have increased the size of the Rvil5 ( $V r 2)$ resistance region, causing an amplification of the distance between the markers and, thus, explaining the higher number of TNL found in the Rvil5 ( $V r 2)$ resistance locus. Moreover, tandem duplication at the Rvil5 ( Vr2) locus could have caused the shift of the gene-rich region found in the Florina sequence (ABC transporters, protein kinase, and so on) (Galli et al. in press, a) and explain the absence of these genes in the sequenced BAC of GMAL 2473.

\section{Isolation of the Rvi15 ( $\mathrm{Vr} 2$ ) candidate genes.}

Three transcribed genes of the TNL family have been found clustered in the Rvil5 ( $V r 2)$ region delimited by the two markers ARGH17 and 77G20 RP. $V r 2-B$ and $V r 2-C$ have been identified between the two markers. The third candidate gene ( $V r 2-$ $A$ ) was found to contain the ARGH17 marker and, therefore, is located on the border of the hot region. The next mapped marker is $43 \mathrm{M} 10 \mathrm{RP}$, which is co-segregating with the resistance. Although this marker is only $4,224 \mathrm{bp}$ from the ARGH17 (1,335 bp from the stop codon of the $V r 2-A)$, three recombination events were identified in this small distance (one susceptible and two resistant progenies). Crossing-overs may have happened within the gene, leading to the loss or gain of functionality of $V r 2-A$. Therefore, we tend to not exclude $V r 2-A$ as a candidate $R v i 15(V r 2)$ gene.

Variation in numbers of motifs in the LRR domain are common between resistance genes and RGH, such as for RPP5 of Arabidopsis (Noël et al. 1999), Cf-2 of tomato (Dixon et al. 1998), Pm3 alleles in wheat (Yahiaoui et al. 2004), and HcrVfs (Vinatzer et al. 2001). Models explaining this variation in numbers of LRR motifs have been based on unequal crossingover or template slippage (Noël et al. 1999; Kuang et al. 2004) and on illegitimate recombination between the LRR units (Wicker et al. 2007). Although unequal crossing-over requires mispairing between two highly similar stretches of at least dozens (usually hundreds) of base pairs, illegitimate recombination requires only a few base pairs (Wicker et al. 2007). Applying these models on the $V r 2-B$ LRR domain suggests that an unequal intragenic recombination based on the mispairing between the $\mathrm{E}$ and the $\mathrm{H}$ motifs could duplicate the $\mathrm{F}, \mathrm{G}$, and $\mathrm{H}$ motifs in the ancestral A to $\mathrm{O}$ sequence of LRR motifs. On the other hand, mispairing between the I motifs with the B motifs or with the first part of the $\mathrm{C}$ terminus of the LRR domain could duplicate the whole block of $\mathrm{C}$ to I motifs (with or without duplicated $\mathrm{F}$ to $\mathrm{H}$ ). It has been proposed that these mechanisms of LRR motif duplications contribute to the diversification of the members of the cluster and, therefore, contribute substantially to the evolution of new $R$ gene specificities (Noël et al. 1999; Wicker et al. 2007). The evident LRR shuffling of the $\operatorname{Vr} 2-B$ gene and the putative tandem duplication discussed above suggest that some of the evolutionary mechanisms characteristic of $R$ gene cluster are or were going on at the Rvil5 (Vr2) locus for the TNL gene cluster. Thus, the presence of such evolutionary mechanisms typical of $R$ gene clusters is another factor that could indicate that the three TNL genes are good Rvil5 ( $V r 2)$ candidate resistance genes.

However, only complementation or silencing experiments of the three candidate genes will allow the determination of which of the three candidates are responsible for the Rvil5 ( $V r 2)$ resistance. Once this information is available, it will be possible, by genetic modification, to pyramid two apple scab resistance genes in a single background.

\section{Conclusion.}

TNL proteins have been found to elicit resistance to many pathogens in different species; for example, against fungal pathogens such as downy mildew in Arabidopsis (RPP5 [Parker et al. 1997] and RPPI [Botella et al. 1998]) and rust in flax ( $M$ [Anderson et al. 1997] and L6 [Lawrence et al. 1995]). Unlike the mentioned fungal pathogens, $V$. inaequalis has a hemibiotrophic life cycle characterized by a saprophytic phase in autumn and winter and a parasitic phase in spring and summer (MacHardy et al. 2001). During the parasitic phase, the pathogen invasion is restricted to the space between the cuticle and the epidermis without formation of specialized organs for nutrient absorption, such as haustoria. Moreover, no appreciable damage to the host tissue is observed in compatible interactions during the time frame from the first to the third week after infection. Only a restricted degradation of the cell wall at the site of penetration is observable (MacHardy 1996). The general opinion is that the pathogen might absorb nutrients only from the subcuticular space (MacHardy 1996). Considering these points of views, the fact that the candidates for Rvil5 $(V r 2)$ resistance are three TNL genes, which are cytoplasmic proteins (Hammond-Kosack and Parker 2003), could generate some doubts. How can the avirulence (Avr) factor enter into contact with the cytoplasmatic TNL if no interactions between pathogen and cell membrane are observed? Why should the pathogen "send" an Avr factor inside the plant cell (and risk being detected) if nutrients are absorbed from the subcuticular space? It has been suggested that $R$ genes directly or indirectly recognize the Avr factor of the pathogen (Dangl and Jones 2001). Therefore, an indirect recognition of the Avr factor by the Rvi15 ( $V r 2)$ protein, for example, i) recognizing a product from the cuticle degradation, which passed the cell wall, or ii) recognizing a product from the reduced degradation of the cell wall observed after infection at the point of pathogen penetration (MacHardy 1996), is still congruent to the main thinking presented above for pathogen nutrient absorption. On the other hand, a direct recognition of the pathogen would evidence a direct interaction between the plant cells and the pathogen, revealing a new biological aspect of this pathosystem. For example, the pathogen Avr factor could redirect assimilates from the leaf to the pathogen penetration site. Therefore, the results presented in this article could provide a challenging and solid foundation for further studies aiming to understand the mechanism of resistance provided by the Rvil5 ( $V r 2)$ gene and the interactions between Malus spp. and $V$. inaequalis. 


\section{MATERIALS AND METHODS}

Construction of BAC libraries.

Young leaves were harvested from 1-year-old grafted trees of GMAL 2473 and stored at $-80^{\circ} \mathrm{C}$ until needed.

Isolation of nuclei for the construction of the first BAC library was performed following the method of Zhang and associates (1995) with the modifications of Vinatzer and associates (1998). Summarizing, partial digestion of the embedded high molecular eight (HMW) DNA was obtained by varying the amount of EcoRI units for reaction (10, 20, 30, and 50 units of enzyme per reaction). After two size selections through pulsed-field gel electrophoresis (PFGE), DNA fragments of between 200 and $400 \mathrm{~kb}$ were selected and mixed with pCC1BAC EcoRI cloning-ready vector (Epicentre Technologies Corp., Madison, WI, U.S.A.) at a molar ratio of 7:1 for ligation following the manufacturer's instruction. Ligation $(1 \mu \mathrm{l})$ was mixed with $20 \mu \mathrm{l}$ of Escherichia coli TransforMax EPI300 electrocompetent cells (Epicentre Technologies Corp.,) for transformation by electrophoresis. After insert size estimation through NotI restriction digestion of 84 generated BAC clones (Galli et al. in press, a), serial transformation was started. Recombinant white clones were picked using the QPix robot $(\mathrm{Ge}-$ netix Ltd., New Milton, Hampshire, U.K.) available at the Functional Genomic Center (ETH Zürich) and, after overnight growth at $37^{\circ} \mathrm{C}$ and $200 \mathrm{rpm}$ in an orbital shaker, were stored at $-80^{\circ} \mathrm{C}$. High-density colony filters were made from the arrayed libraries using the Biomek 2000 robot (Beckman, Fullerton, CA, U.S.A.) at the Amplicon Express Inc.. Clones were doublespotted onto Hybond N+ membrane (GE Healthcare Limited, Buckinghamshire, U.K.) in a three-by-three format according to Zhang and associates (1996).

The second BAC library was constructed at the Amplicon Express Inc. from frozen GMAL 2473 leaf material after Tao and associates (2002). This BAC library has been constructed with a partial HindIII digestion and cloned into pECBAC1 (Epicentre). BAC clones were picked and also double-spotted onto Hybond N+ membrane (GE Healthcare Limited) in a threeby-three format according to Zhang and associates (1996). The average insert size of the BAC library was estimated by NotI restriction digestion of 28 randomly selected BAC clones.

\section{Construction of the BAC contig spanning the Rvi15 ( $V r 2)$ resistance locus.}

After radiolabeled BAC library screening as described in Patocchi and associates (1999), positive BAC clones were used to start overnight cultures at $37^{\circ} \mathrm{C}$ on a Luria-Bertani agar plate containing chloramphenicol at $12.5 \mu \mathrm{g} / \mu \mathrm{l}$. To verify the hybridization result, a single colony of positive BAC was resuspended in $50 \mu \mathrm{l}$ of double-distilled $(\mathrm{dd}) \mathrm{H}_{2} \mathrm{O}$ and denatured for $5 \mathrm{~min}$ at $95^{\circ} \mathrm{C}$. The solution $(5 \mu \mathrm{l})$ was then used as template in polymerase chain reaction (PCR) amplifications employing the specific primers of the marker used for screening. BAC clones not positive to the PCR were excluded from further analysis. Amplicons obtained from the positive ones were analyzed following the marker criteria to identify the BAC clones originating from the chromosome carrying the resistance. DNA from positive BAC clones was extracted following a standard alkaline lyses procedure (Birnboim and Doly 1979). BAC insert extremities were sequenced as described by Galli and associates (in press, a). Two fingerprints of all positive BAC were generated by performing an EcoRI and HindIII restriction digestion.

Two approaches were used to identify the overlapping ends of the BAC and the external ends of the growing BAC contig. In the first approach, all specific BAC-end primer pairs were used in PCR to test their ability to amplify from the clones found during the screening of the library. The primer pair, which produced an amplicon only from the clone from which it was generated, was considered to be the extremity of the contig. Similarly, primer pairs which produced amplicons from more than a BAC were considered to be overlapping with that group of BAC. The second approach consisted in hybridizing the EcoRI and HindIII Southern blots carrying digested DNA of all BAC with labeled PCR product generated with the specific BAC-end primer pair. Again, the BAC end that hybridized only to the clone from which it was derived or to an EcoRI and a HindIII restriction fragment not present in the other clones (in cases where the corresponding sequence was repeated in the region) was considered to be the extremity of the contig. PCR products generated with the specific BAC end primer pair, hybridizing with a group of BAC, were considered to be overlapping with that group of BAC.

Development and mapping of new polymorphic markers (allowing the orientation of the BAC contig) were performed as described by Galli and associates (in press, a). Briefly, the two parents (GMAL2473 and Golden Delicious), a set of 10 resistant and 10 susceptible progeny plants, and the 56 recombinant progenies detected in the cross Golden Delicious $\times$ GMAL 2473 between the $\mathrm{CH} 02 \mathrm{c02a}$ and $\mathrm{CH} 02 \mathrm{fO6}$ microsatellites mapping on both side of the Rvil5 ( $V r 2)$ resistance locus were analyzed.

\section{BAC clone sequencing.}

The 32A4 BAC clone, spanning the Rvil5 (Vr2) resistance locus, was shotgun sequenced at the Genome Sequencing Center (Washington University, St. Louis, MO, U.S.A.). A 10x coverage draft sequence of the BAC clone was assembled by the company using Fingerprint and Assembly Incorporation software (FASSI) length constraints in conjunction with PCAP.REP (Huang et al. 2006). The consensus sequence was verified comparing the restriction map of the sequence with the pattern of four fingerprint digestions (EcoRI, HindIII, $E c o \mathrm{RV}$, and $S a c \mathrm{I}$ ) and the BAC insert size. Further, the sequences provided by the company have been double checked using the software Sequencer (Genecodes Corp. Ann Arbor, MI, U.S.A.). Vector was trimmed using the specific software function and the sequences were then assembled with a high stringency (95\% match, 20-bp minimum overlap) and aligned with the contigs provided by the company. The verified contigs were then aligned to the sequences of the BAC extremities obtained during the construction of the BAC contig and to the marker alleles in coupling with the resistance to identify their physical position. Gaps between the contigs present in the sequence delimited by the two Rvi15 ( Vr2) closest markers (bracketing the resistance) were filled by primer walking.

\section{Identification of $R v i 15(\mathrm{Vr} 2)$ candidate genes.}

The 32A4 BAC sequence was blasted against all nucleotide sequences (BLASTN) deposited at the NCBI database to localize all the sequences in the contig showing similarity to characterized sequences. ORF predictions were then performed with the softwares FGENESH 2.6 (Salamov and Solovyev 2000), CLC, and GENSCAN (Burge and Karlin 1997). Obtained ORF were blasted against the protein sequences (BLASTX) deposited at the NCBI database and analyzed with the Conserved Domain tools of the NCBI. ORF showing no similarity to any sequence of the databases were excluded from further analysis. Similarity at nucleotide and amino acid levels was calculated using CLUSTALW2 (Larkin et al. 2007) of EMBL-EBI.

\section{Transcription analysis of $R v i 15(\mathrm{Vr} 2)$ candidate genes.}

Total RNA was extracted from uninfected young leaves of 2year-old grafted GMAL 2473 trees using the SV Total RNA 
Isolation System (Promega Corp., Madison, WI, U.S.A.) following the manufacturer's instructions. First-strand cDNA was then synthesized in a Perkin-Elmer Cetus Gene Amp PCR System 9600 with the Protoscript kit (New England Biolabs, Ipswich, MA, U.S.A.) following the manufacturer's instructions. Specific primer pairs, designed with Primer3 software (Rozen and Skaletsky 2000) on the candidate genes, were then used to amplify part of the predicted genes in a long PCR amplification from the whole cDNA as follows: $5 \mu \mathrm{l}$ of cDNA solution was mixed with $5 \mu \mathrm{l}$ of $10 \times$ long PCR buffer with $\mathrm{MgCl}_{2}, 0.2$ $\mathrm{mM}$ each dNTP, $20 \mathrm{pmol}$ of each primer, and $1 \mathrm{U}$ of long PCR enzyme mix (Fermentas, Vilnius, Lithuania ) in a total volume of $50 \mu \mathrm{l}$. The thermal cycling conditions were initial denaturation at $94^{\circ} \mathrm{C}$ for $2 \mathrm{~min}$; followed by 10 cycles of $40 \mathrm{~s} 94^{\circ} \mathrm{C}, 40 \mathrm{~s}$ at $60^{\circ} \mathrm{C}$, and $3.5 \mathrm{~min}$ at $68^{\circ} \mathrm{C}$; and 20 cycles with the same profile as above but with $10 \mathrm{~s}$ more in the extension step. Finally, a 10 -min PCR extension was carried out at $68^{\circ} \mathrm{C}$. Primers used were ARGH17 forward (5'-AGCGAAGCGGACTTCATTAG$\left.3^{\prime}\right)$ and ORF11R (5'-ATGCATCATGGCTTGGTCCTC-3') for $V r 2-A ; 10-1 \mathrm{aF}\left(5^{\prime}\right.$-CTTAATGGCTGTTACAGTCTCAG-3') and sp10-1cR (5'-GCAGTTCTATGAATTCTAAACATCC-3') for $V r 2-B$; and 10-2aF (5'-TCACCATTGTTTTGGTCCAG-3') and ORF2-10R (5'-GTGTTTGACGAATTGATTGTGATG-3') for Vr2-C. Obtained amplicons were purified with the NucleoFast kit (Macherey-Nagel, Dueren, Germany) following the manufacturer's instructions and resuspended in $50 \mu \mathrm{l}$ of $\mathrm{ddH}_{2} \mathrm{O}$. Then, $5 \mu$ l was used as template in a sequencing reaction using the BigDye Terminator kit 3.1 (Applied Biosystems, Foster City, CA, U.S.A.). Sequencing reactions consisted of 99 cycles of $30 \mathrm{~s}$ at $96^{\circ} \mathrm{C}, 20 \mathrm{~s}$ at $50^{\circ} \mathrm{C}$, and $4 \mathrm{~min}$ at $60^{\circ} \mathrm{C}$. Reaction products were separated on ABI 3100 DNA sequencing system (Applied Biosystems). The obtained sequences were then aligned with the software Sequencer (Genecodes) to the respective ORF.

\section{ACKNOWLEDGMENTS}

We thank the Swiss Federal Institute of Technology for financing this project, the Swiss Federal Station of Wädenswil (ACW) for providing all the plant material, the Functional Genomic Center of the Swiss Federal Institute of Technology (Zürich), and the ETH for their support through grant TH-11/04-2.

\section{LITERATURE CITED}

Anderson, P. A., Lawrence, G. J., Morrish, B. C., Ayliffe, M. A., Finnegan, E. J., and Ellis, J. G. 1997. Inactivation of the flax rust resistance gene $M$ associated with loss of a repeated unit within the leucine-rich repeat coding region. Plant Cell 9:641-651.

Arumunagathan, K., and Earle, E. D. 1991. Nuclear DNA content of some important plant species. Plant Mol. Biol. Rep. 9:229-241.

Belfanti, E., Silfverberg-Dilworth, E., Tartarini, S., Patocchi, A., Barbieri, M., Zhu, J., Vinatzer, B. A., Gianfranceschi, L., Gessler, C., and Sansavini, S. 2004. The HcrVf2 gene from a wild apple confers scab resistance to a transgenic cultivated variety. Proc. Nat. Acad. Sci. U.S.A. 101:886-90.

Bénaouf, G., and Parisi, L. 2000. Genetics of host-pathogen relationships between Venturia inaequalis races 6 and 7 and Malus species. Phytopathology 90:236-242.

Bent, A. F., Kunkel, B. N., Dahlbeck, D., Brown, K. L., Schmidt, R., Giraudat, J., Leung, J., and Staskawicz, B. J. 1994. Rps 2 of Arabidopsis thaliana a leucine-rich repeat class of plant-disease resistance genes. Science 265:1856-1860.

Birnboim, H. C., and Doly, J. 1979. Rapid alkaline extraction procedure for screening recombinant plasmid DNA. Nucleic Acids Res. 7:15131523.

Botella, M. A., Parker, J. E., Frost, L. N., Bittner-Eddy, P. D., Beynon, J. L., Daniels, M. J., Holub, E. B., and Jones, J. D. G. 1998. Three genes of the Arabidopsis RPP1 complex resistance locus recognize distinct Peronospora parasitica avirulence determinants. Plant Cell 10:18471860.

Burge, C., and Karlin, S. 1997. Prediction of complete gene structures in human genomic DNA. J. Mol. Biol. 268:78-94.

Bus, V. G. M., Rikkerink, E., Aldwinckle, H. S., Caffier, V., Durel, C-E., Gardiner, S., Gessler, C., Groenwold, R., Laurens, F., Le Cam, B., Luby, J., MacHardy, W., Meulenbroek, B., Kellerhals, M., Parisi, L., Patocchi, A., Plummer, K., Schouten, H. J., Tartarini, S., and van de Weg, W. E. 2009. A proposal for the nomenclature of Venturia inaequalis races. Acta Hortic. 814:739-746.

Crandall, C. S. 1926. Apple breeding at the University of Illinois. Ill. Agric. Exp. Stn. Bull. 275:341-600.

Dangl, J. L., and Jones, J. D. G. 2001. Plant pathogens and integrated defence responses to infection. Nature 411:826-833.

Dixon, M. S., Hatzixanthis, K., Jones, D. A., Harrison, K., and Jones, J. D. G. 1998. The tomato $C f-5$ disease resistance gene and six homologs show pronounced allelic variation in leucine-rich repeat copy number. Plant Cell 10:1915-1925.

Feuillet, C., Travella, S., Stein, N., Albar, L., Nublat, A., and Keller, B. 2003. Map-based isolation of the leaf rust disease resistance gene Lr10 from the hexaploid wheat (Triticum aestivum L.) genome. Proc. Nat. Acad. Sci. U.S.A. 100:15253-15258.

Frijters, A. C. J., Zhang, Z., vanDamme, M., Wang, G. L., Ronald, P. C., and Michelmore, R. W. 1997. Construction of a bacterial artificial chromosome library containing large EcoRI and HindIII genomic fragments of lettuce. Theor. Appl. Genet. 94:390-399.

Galli, P., Broggini, G. A. L., Gessler, C., and Patocchi, A. High-resolution genetic map of the Rvil5 ( Vr2) apple scab resistance locus. Mol. Breed. In press, $\mathrm{a}$.

Galli, P., Broggini, G. A. L., Gessler, C., and Patocchi, A.. Phenotypic characterization of the Rvi15 (Vr2) apple scab resistance gene. J. Plant Pathol. In press, b.

Gardiner, S. E., Bus, V. G. M, Rusholme, R. L., Chagné, D. and Rikkerink, E. H. A. 2007. Apple. Pages 1-62 in: Fruits and Nuts, Genome Mapping and Molecular Breeding in Plants, vol. 4. C. Kole, ed. Springer, Berlin.

Gessler, C., Vanblaere, T., Szankowski, I., and Broggini, G. A. L. 2009. Cisgenic approach to disease resistance in apple. (Abstr.) Phytopathology 99:S42.

Hammond-Kosack, K. E., and Parker, J. E. 2003. Deciphering plant-pathogen communication: fresh perspectives for molecular resistance breeding. Curr. Opin. Biotechnol. 14:177-193.

Huang, X. Q., Yang, S. P., Chinwalla, A. T., Hillier, L. W., Minx, P., Mardis, E. R., and Wilson, R. K. 2006. Application of a superword array in genome assembly. Nucleic Acids Res. 34:201-205.

Jacobsen, E., and Schouten, H. J. 2007. Cisgenesis strongly improves introgression breeding and induced translocation breeding of plants. Trends Biotechnol. 25:219-223.

Jones, D. A., and Jones, J. D. G. 1997. The role of leucine-rich repeat proteins in plant defences. Adv. Bot. Res. 24:89-167.

Kuang, H., Woo, S. S., Meyers, B. C., Nevo, E., and Michelmore, R. W. 2004. Multiple genetic processes result in heterogeneous rates of evolution within the major cluster disease resistance genes in lettuce. Plant Cell 16:2870-2894.

Larkin, M. A., Blackshields, G., Brown, N. P., Chenna, R., McGettigan, P. A., McWilliam, H., Valentin, F., Wallace, I. M., Wilm, A., Lopez, R., Thompson, J. D., Gibson, T. J., and Higgins, D. G. 2007. ClustalW2 and ClustalX version 2. Bioinformatics 23:2947-2948.

Lawrence, G. J., Finnegan, E. J., Ayliffe, M. A., and Ellis, J. G. 1995. The L6 gene for flax rust resistance is related to the Arabidopsis bacterialresistance gene Rps 2 and the tobacco viral resistance gene $N$. Plant Cell 7:1195-1206

MacHardy, W. E. 1996. Apple Scab, Biology, Epidemiology and Management. American Phytopathological Society Press, St. Paul, MN, U.S.A.

MacHardy, W. E., Gadoury, D. M., and Gessler, C. 2001. Parasitic and biological fitness of Venturia inaequalis: relationship to disease management strategies. Plant Dis. 85:1036-1051.

Malnoy, M., Xu, M., Borejsza-Wysocka, E., Korban, S. S., and Aldwinckle, H. S. 2008. Two receptor-like genes, Vfal and $V f a 2$, confer resistance to the fungal pathogen Venturia inaequalis inciting apple scab disease. Mol. Plant-Microbe Interact. 21:448-458.

Martin, G. B., Devicente, M. C., and Tanksley, S. D. 1993. High-resolution linkage analysis and physical characterization of the Pto bacterial-resistance locus in tomato. Mol. Plant-Microbe Interact. 6:26-34.

Meyers, B. C., Kozik, A., Griego, A., Kuang, H. H., and Michelmore, R. W. 2003. Genome-wide analysis of NBS-LRR-encoding genes in Arabidopsis. Plant Cell 15:1683-1683.

Michelmore, R. W., and Meyers, B. C. 1998. Clusters of resistance genes in plants evolve by divergent selection and a birth-and-death process. Genome Res. 8:1113-1130.

Noël, L., Moores, T. L., van der Biezen, E. A., Parniske, M., Daniels, M. J., Parker, J. E., and Jones, J. D. G. 1999. Pronounced intraspecific haplotype divergence at the RPP5 complex disease resistance locus of Arabidopsis. Plant Cell 11:2099-2111. 
Parisi, L., Lespinasse, Y., Guillaumes, J., and Kruger, J. 1993. A new race of Venturia inaequalis virulent to apples with resistance due to the Vf gene. Phytopathology 83:533-537.

Parker, J. E., Coleman, M. J., Szabo, V., Frost, L. N., Schmidt, R. vanderBiezen, E. A., Moores, T., Dean, C., Daniels, M. J., and Jones, J. D. G. 1997. The Arabidopsis downy mildew resistance gene RPP5 shares similarity to the toll and interleukin-1 receptors with $N$ and $L 6$. Plant Cell 9:879-894.

Patocchi, A., Vinatzer, B. A., Gianfranceschi, L., Tartarini, S., Zhang, H. B., Sansavini, S., and Gessler, C. 1999. Construction of a $550 \mathrm{~kb}$ BAC contig spanning the genomic region containing the apple scab resistance gene Vf. Mol. Gen. Genet. 262:884-891.

Patocchi, A., Bigler, B., Koller, B., Kellerhals, M., and Gessler, C. 2004. Vr2: a new apple scab resistance gene. Theor. Appl. Genet. 109:10871092.

Roberts, A. L., and Crute, I. R. 1994. Apple scab resistance from Malus floribunda $821(V f)$ is rendered ineffective by isolates of Venturia inaequalis from Malus floribunda. Norw. J. Agric. Sci. Suppl. 17:403-406.

Rozen, S., and Skaletsky, H. J. 2000. Primer3 on the WWW for general users and for biologist programmers. Pages 365-386 in: Bioinformatics Methods and Protocols. S. Misener and S. Krawetz, eds. Humana Press, Totowa, NJ, U.S.A.

Salamov, A. A., and Solovyev, V. V. 2000. Ab initio gene finding in Drosophila genomic DNA. Genome Res. 10:516-522.

Smith, S. M., Pryor, A. J., and Hulbert, S. H. 2004. Allelic and haplotypic diversity at the Rp1 rust resistance locus of maize. Genetics 167:19391947.

Song, W. Y., Wang, G. L., Chen, L. L., Kim, H. S., Pi, L. Y., Holsten, T., Gardner, J., Wang, B., Zhai, W. X., Zhu, L. H., Fauquet, C., and Ronald, P. 1995. A receptor kinase-like protein encoded by the rice disease resistance gene, Xa21. Science 270:1804-1806

Szankowski, I., Waidmann, S., Degenhardt, J., Patocchi, A., Paris, R., Silfverberg-Dilworth, E., Broggini, G., and Gessler, C. 2009. Highly scab-resistant transgenic apple lines achieved by introgression of HcrVf2 controlled by different native promoter lengths. Tree Genet. Genomes 5:349-358.
Tao, Q., Wang, A., and Zhang, H. B. 2002. One large-insert plant-transformation-competent BIBAC library and three BAC libraries of Japonica rice for genome research in rice and other grasses. Theor. Appl. Genet. 105:1058-1066.

Vinatzer, B. A., Zhang, H. B., and Sansavini, S. 1998. Construction and characterization of a bacterial artificial chromosome library of apple. Theor. Appl. Genet. 97:1183-1190.

Vinatzer, B. A., Patocchi, A., Gianfranceschi, L., Tartarini, S., Zhang, H. B., Gessler, C., and Sansavini, S. 2001. Apple contains receptor-like genes homologous to the Cladosporium fulvum resistance gene family of tomato with a cluster of genes cosegregating with $V f$ apple scab resistance. Mol. Plant-Microbe Interact. 14:508-515.

Whitham, S., Dineshkumar, S. P., Choi, D., Hehl, R., Corr, C., and Baker, B. 1994. The product of the tobacco mosaic-virus resistance gene $N$ similarity to Toll and the interleukin-1 receptor. Cell 78:1101-1115.

Wicker, T., Yahiaoui, N., and Keller, B. 2007. Illegitimate recombination is a major evolutionary mechanism for initiating size variation in plant resistance genes. Plant J. 51:631-641.

Xu, M. L., and Korban, S. S. 2002. A cluster of four receptor-like genes resides in the $V f$ locus that confers resistance to apple scab disease. Genetics 162:1995-2006.

Yahiaoui, N., Srichumpa, P., Dudler, R., and Keller, B. 2004. Genome analysis at different ploidy levels allows cloning of the powdery mildew resistance gene Pm3b from hexaploid wheat. Plant J. 37:528-538.

Zhang, H. B., Zhao, X. P., Ding, X. L., Paterson, A. H., and Wing, R. A. 1995. Preparation of Megabase-Size DNA from plant nuclei. Plant J. 7:175-184.

Zhang, H. B., Choi, S. D., Woo, S. S., Li, Z. K., and Wing, R. A. 1996. Construction and characterization of two rice bacterial artificial chromosome libraries from the parents of a permanent recombinant inbred mapping population. Mol. Breed. 2:11-24.

\section{AUTHOR-RECOMMENDED INTERNET RESOURCE}

CLC bio website: www.clcbio.com 